\title{
O Desafio de Aprender a Aprender na Formasão de Professores de Línguas Estrangeiras
}

\author{
The Challenge of Learning to Learn in Foreign Languages \\ Teachers Pre Service Training
}

Myriam Crestian CUNHA*
Walkyria Magno e SILVA**

Resumo: Embora estudos teóricos sobre estratégias de aprendizagem sejam comuns nas publicações da área do ensino/aprendizagem de línguas estrangeiras, são menos frequentes pesquisas que visem avaliar o uso dessas estratégias a médio e longo prazo. O presente estudo analisa o impacto da disciplina "Aprender a Aprender Línguas Estrangeiras", incluída há poucos anos na licenciatura de Letras (inglês e francês), observando em que medida os diferentes tipos de estratégias ensinados foram incorporados na rotina dos professores em formação. São tratados dados quantitativos provenientes de um questionário e dados qualitativos oriundos de narrativas escritas de aprendentes na fase mediana do curso. Os resultados mostram uma clara ampliação do uso das estratégias, com destaque às metacognitivas, mas também evidencia os desafios que o desenvolvimento de uma postura reflexiva impõe no contexto brasileiro, apontando para os benefícios, por um lado, de um ensino estratégico integrado ao ensino da língua e, por outro, de uma regência de aulas mais precoce.

Palavras-chave: Aprender a Aprender. Estratégias de aprendizagem. Avaliação do uso de estratégias.

\footnotetext{
* Doutora em Ciências da Linguagem pela Universidade de Toulouse II-Le Mirail, França (1998). Professora da Universidade Federal do Pará. Contato: mycunha@gmail.com.

** Doutora em Ciências da Linguagem pela Universidade de Toulouse II-Le Mirail, França (2002). Professora da Universidade Federal do Pará. Contato: walkyriamagno@gmail.com.
} 


\begin{abstract}
This text, aiming at filling a gap in recent learning strategies related studies, reports a study conducted to measure if and to what extent strategies practiced by undergraduates majoring in French and English were incorporated in their study routines. A questionnaire provided data for quantitative analysis and language learning histories contributed with qualitative information on the process. Both were produced after three to five semesters of its first instruction in a discipline called Learning to Learn Foreign Languages. Results show that a great deal of strategies, beforehand unknown to the students, were incorporated in their routines. A special role was given to the metacognitive strategies, which focus on reflection skills. Results also stress that the challenges enhanced by a reflective posture in the Brazilian context, demand, on the one hand, the benefits of a strategic teaching integrated to language teaching and, on the other hand, an early insertion in teaching practicum.
\end{abstract}

Key words: Learning to Learn Foreign Languages. Learning strategies. Strategies use assessment.

\title{
Introdução
}

Há algumas décadas a autonomia na aprendizagem de línguas tem sido estudada e incentivada. Desde o trabalho seminal de Holec (1981), várias pesquisas foram realizadas, algumas delas historiadas em Benson (2001) ou publicadas em livros e periódicos nacionais e estrangeiros. No entanto, em termos de projeto didático-metodológico na formação de futuros professores, o desenvolvimento da autonomia ainda constitui um desafio, principalmente quando envolve alunos pouco motivados que escolhem o curso por ele oferecer menos concorrência, como é frequentemente o caso em línguas minoritárias, como o francês.

$\mathrm{Na}$ busca pela sempre sonhada transformação de alunos pouco engajados em futuros professores conscientes e autônomos, os cursos de Letras com habilitação em alemão, espanhol, francês e inglês, da Faculdade de Letras Modernas Estrangeiras da Universidade Federal do Pará (UFPA), introduziram em seu Projeto Pedagógico (UFPA, 2009) a disciplina "Aprender a Aprender Línguas Estrangeiras" (doravante Ap/Ap). Essa disciplina, ministrada no primeiro semestre do curso para todos os licenciandos em línguas estrangeiras (doravante LE), visa à sua conscientização em relação às 
exigências da aprendizagem da LE, mediante a objetivação desse processo. Ao conscientizar-se de sua inserção particular em temas tais como motivação, crenças, papéis do professor e do aluno, estratégias e estilos de aprendizagem, o aprendente inicia um processo reflexivo suscetível de torná-lo mais apto a controlar e regular sua aprendizagem e a alcançar uma maior autonomia em sua formação inicial.

A experiência, que já se desenvolve há quatro anos, representa um duplo desafio: por um lado, os formadores precisam encontrar uma metodologia adequada, que fuja à mera exposição de conceitos sobre os temas do programa e proporcione aos novos alunos uma real vivência do processo reflexivo pretendido. Por outro, esses alunos, muitas vezes, iniciantes completos na aprendizagem do idioma, são confrontados a exigências totalmente diferentes das do ensino básico, precisando assumir a responsabilidade não só pela avaliação e regulação de suas competências comunicativas (como estão indo em relação aos objetivos comunicativos definidos), como ainda pela avaliação e regulação de seu processo de aprendizagem (que estratégias estão usando para aprender e como gerenciam seu próprio estudo) ${ }^{1}$.

Para os professores da disciplina, as ricas experiências vivenciadas no acompanhamento dos aprendentes, durante esse processo de autodescoberta, inteiramente novo para muitos, têm se transformado em objeto de investigações.

Neste artigo relatamos uma das pesquisas empreendidas para analisar o impacto dessa disciplina, em médio prazo, no que diz respeito, mais especificamente, ao uso de estratégias de aprendizagem em sua formação de falantes da LE.

Para tal, procuramos identificar, junto a 30 licenciandos de francês e inglês dos segundo e terceiro anos do curso, se o modo como lidavam com estratégias de aprendizagem havia se modificado após terem cursado Ap/Ap. As informações, obtidas por meio de um questionário aplicado a esses alunos e de uma narrativa produzida por eles, geraram dados tanto

${ }^{1}$ Em sua descrição dos cinco componentes da aprendizagem, Allal (2007, p. 9) arrola os processos de regulação como um desses componentes, ao lado das atividades cognitivas e metacognitivas, das atividades afetivas, das atividades sociais e dos produtos que resultam da transformação (planos mental e material). 
quantitativos quanto qualitativos que serão expostos aqui, após um rápido apanhado teórico a respeito de estratégias de aprendizagem.

\section{Referencial Teórico}

Os estudos sobre estratégias de aprendizagem, desenvolvidos já há mais de três décadas, não constituem mais nenhuma novidade teórica no campo do ensino e aprendizagem de línguas estrangeiras. Todavia, sua aprendizagem, sinônima ao desenvolvimento de competências procedimentais, ainda esbarra em um grande número de fatores, nem sempre facilmente apreensíveis. Diversos autores (BROWN et al., 1983; WENDEN, 1987; O'MALLEY; CHAMOT, 1990; OXFORD, 1990) descreveram e classificaram essas diferentes ações dos aprendentes para se tornarem proficientes em uma LE. As taxonomias elaboradas por alguns deles mencionam as estratégias cognitivas como tendo um papel no emprego da língua sendo aprendida, e as metacognitivas como aquelas que regem o processo de aprendizagem e organizam a utilização das estratégias cognitivas e socioafetivas. O pesquisador canadense $\operatorname{Cyr}(1998$, p. 40), ao sintetizar esses estudos, considera a classificação de O’Malley e Chamot “[...] a mais sintética, a mais rigorosa e a mais solidamente ancorada nos conceitos e teorias da psicologia cognitiva". Veremos aqui, porém, que essas taxonomias concordam em muitos aspectos.

Segundo Oxford (1990, p. 43), as estratégias cognitivas têm a função de "[...] fazer com que o aprendente manipule e transforme a língua alvo". Essas estratégias - as mais utilizadas por serem aquelas tradicionalmente praticadas em sala de aula - abrangem um grande número de ações como praticar e analisar a língua, bem como criar situações para seu uso. O’Malley e Chamot (1990, p. 44) ressaltam que elas “[...] operam diretamente sobre a informação que chega, manipulando-a de forma a potencializar a aprendizagem”. Para eles, tais estratégias englobam: praticar a língua; lembrar, organizar e classificar palavras, tendo em vista o aumento do vocabulário; resumir e sintetizar; deduzir; usar imagens para compreender e lembrar das informações ${ }^{2}$; transferir o conhecimento para outras situações; entre outras. Em síntese, "implicam uma interação entre o aprendente e a matéria em estudo, uma manipulação

2 Oxford (1990) distingue as estratégias cognitivas das de memória, contrariamente a O’Malley e Chamot (1990). 
mental e física dessa matéria e a aplicação de técnicas específicas para resolver um problema ou executar uma tarefa de aprendizagem" (CYR, 1998, p. 46-47).

As estratégias metacognitivas, para Oxford (1990, p. 136), “[...] proporcionam um meio para que os aprendentes coordenem seu próprio processo de aprendizagem”. Segundo O’Malley e Chamot (1990, p. 44), elas "[...] envolvem o planejamento, o monitoramento e a avaliação dos resultados da aprendizagem", o que, para Cyr (1998, p. 42), consiste "[...] em refletir sobre o seu processo de aprendizagem, em compreender as condições que o favorecem, em organizar ou planejar suas atividades com vistas à concretização das aprendizagens, em auto-avaliar-se e autocorrigir-se". De maneira geral, os estudiosos enfatizam a necessidade de os aprendentes se tornarem mais reflexivos e críticos para desenvolverem capacidades de objetivação, tanto de sua aprendizagem quanto de suas competências de comunicação, como condição para a autorregulação desses dois processos.

Por considerar que "A afetividade de um aprendente é provavelmente uma das maiores influências no sucesso ou no fracasso de uma experiência de aprendizagem de línguas" (OXFORD, 1990, p. 140), a autora divide as estratégias socioafetivas em dois grupos, ambos na categoria das estratégias indiretas. Ao incluir em sua lista de estratégias afetivas "auto-estima, atitudes, motivação, ansiedade, choque cultural, inibição, tomada de riscos e tolerância em relação à ambigüidade", a autora (1990, p. 140) ressalta a importância de o aprendente saber lidar com todo o tipo de emoções, atitudes, motivações e valores envolvidos na aprendizagem de uma LE. No entanto, percebe-se pouca ênfase, nas aulas e nos materiais didáticos de LE de um modo geral, em relação à dimensão afetiva da aprendizagem.

Finalmente, as estratégias sociais, que Oxford agrupa em três conjuntos (fazer perguntas, cooperar e criar empatia com os outros), são fundamentais para a aprendizagem de línguas, uma vez que a comunicação entre indivíduos é um dos principais objetivos do ensino/aprendizagem de línguas.

Já O’Malley e Chamot não separam as estratégias afetivas das sociais, definindo-as como "[...] um amplo grupo de estratégias que envolvem ou a interação com outrem ou um controle ideacional sobre a afetividade" (1990, p. 45). Promover ações cooperativas, fazer e responder perguntas, pensar em exemplos, falar consigo próprio e usar controle mental são exemplos dessas estratégias socioafetivas.

Todos os autores mencionados apontam para a necessidade de transformar as estratégias em objeto de ensino e de aprendizagem, o que 
vem sendo gradativamente inserido dentro da rotina de salas de aula de LE. Ensinar os alunos a se apropriarem dessas estratégias em benefício próprio passou a fazer parte do trabalho do professor. Praticamente todos os modelos de ensino de estratégias preconizam uma sequência de quatro passos, nos quais uma alta dose de apoio é fornecida no começo da instrução, sendo gradualmente reduzida, até que os aprendentes assumam a responsabilidade pelo seu uso. Os passos são:

1. Conscientização, pelos aprendentes, das estratégias que já são por eles utilizadas;

2. Apresentação e modelagem de estratégias pelo professor, de forma que os aprendentes se tornem cada vez mais conscientes dos seus processos de pensamento e aprendizagem;

3. Oferta de múltiplas oportunidades de prática, para auxiliar os aprendentes a seguirem na direção do uso autônomo das estratégias, por meio da retirada gradual do apoio;

4. Auto-avaliação da eficácia das estratégias utilizadas e transferência dessas estratégias para novas tarefas. (COHEN; MACARO, 2007, p. 142).

Estes passos são preconizados pelos autores para utilização com aprendentes maduros (jovens e adultos), mas também com um público infantil. Diversos procedimentos para explicitar o uso de estratégias são sugeridos, tais como pensar em voz alta e utilizar recursos visuais, para as crianças, e grupos focais e questionários, para jovens e adultos, entre outros.

Estudos mais recentes (COHEN; MACARO, 2007) sobre estratégias tendem a não chamá-las mais de estratégias de aprendizagem, mas sim de estratégias de aprendentes ${ }^{3}$, uma vez que a escolha e o emprego de estratégias adequadas a cada aluno é fruto de um percurso absolutamente individual dentro do processo de apropriação de uma língua adicional. Já o ensino visando ao controle dessas estratégias pelo aprendente tende a assumir maior importância nos dias atuais. Isso fica claro nas palavras de Gu (2007, p. vii):

${ }^{3} \mathrm{O}$ termo "estratégias dos aprendentes de línguas" (language learner strategies) foi primeiramente utilizado em junho de 2004, em uma reunião de 23 pesquisadores da área na Universidade de Oxford (COHEN; MACARO, 2007). 
À medida que aceitamos a importância da agência individual na aprendizagem e concordamos que, além das diferenças individuais, tais como aptidão e motivação, aquilo que os alunos escolhem fazer também faz uma diferença no processo de aprendizagem, deveríamos dar a devida importância aos comportamentos estratégicos dos alunos em uma teoria de aprendizagem, em geral, e na aprendizagem de LE, em particular.

Veremos, em nossos dados, que o desenvolvimento de novas estratégias de aprendizagem passa por um período de amadurecimento interno, ao qual o professor tem pouco acesso, e que algumas novas situações, às vezes externas à aprendizagem, podem alavancar o real emprego dessas estratégias.

\section{Metodologia da Pesquisa}

A fim de investigarmos o efeito da disciplina "Aprender a Aprender Línguas Estrangeiras", voltamo-nos para estudantes das habilitações em inglês e francês que se enquadrassem nos seguintes critérios: terem ingressado no curso em 2010 ou 2011 e ainda permanecerem nele em $2012^{4}$ (o que significa que os sujeitos da pesquisa haviam cursado eventualmente até cinco níveis de estudo da língua); terem cursado a disciplina Ap/Ap no primeiro bloco de aulas; finalmente, se disporem a participar da pesquisa. Os instrumentos utilizados foram um questionário a respeito de seus hábitos no estudo da LE (ver apêndice) e uma narrativa de aprendizagem relativa à sua experiência de aprendizagem decorrida desde seu ingresso na licenciatura ${ }^{5}$.

${ }^{4}$ A pesquisa foi realizada no final de $2^{\circ}$ semestre de 2012 , junto aos alunos do curso matutino de francês e do curso noturno de inglês, que assinaram um termo de consentimento livre e esclarecido quanto ao uso dos dados coletados. Foi solicitado aos estudantes que fossem absolutamente sinceros em suas respostas.

${ }^{5}$ Para a narrativa, foi dado o seguinte comando: No âmbito da disciplina "Aprender a Aprender Linguas Estrangeiras", você escreveu uma narrativa de aprendizagem de linguas, contando como tinh a sido sua experiência de aprendizagem de linguas estrangeiras até ingressar no curso de francês/inglês. Gostaria que você redigisse uma nova narrativa contando sua trajetória daquele ponto em diante, ou seja, mostrando o que aconteceu com a sua aprendizagem de linguas estrangeiras depois que você começou o seu curso de graduação. 
O questionário proposto comportava um total de 18 itens redigidos em forma de afirmações na primeira pessoa do singular (por ex.: "Sistematizo e organizo o que está sendo estudado em sala”), relativas ao uso de estratégias cognitivas, metacognitivas, sociais e afetivas. Os quesitos foram apresentados em ordem aleatória, misturando as diversas categorias de estratégias.

Além disso, o questionário combinava uma escala Likert para determinar a frequência com que o aluno realizava a ação mencionada no item ("sempre”, "às vezes", "quase nunca"; “nunca”), bem como alternativas que permitiam: a) indicar a partir de que momento a adoção daquele hábito tinha ocorrido (antes do ingresso no curso, depois da disciplina Ap/Ap ou em época mais recente); b) se os sujeitos achavam ou não necessário adotar aquele hábito.

Trinta estudantes (sendo 13 de inglês e 17 de francês) preencheram o questionário, o que corresponde a mais de $55 \%$ do total de alunos inscritos naquelas turmas. Deste total, apenas 11 (sendo seis de inglês e cinco de francês) entregaram a nova narrativa.

Os dados quantitativos obtidos com o questionário foram tabulados, com indicação do número de ocorrências encontradas para cada tópico em valor absoluto e seu total em percentual. Algumas respostas consideradas inconsistentes foram indicadas entre colchetes e os valores percentuais correspondentes foram recalculados, deixando-se de lado esses dados inconsistentes (o novo valor percentual também foi indicado entre colchetes, nas tabelas). Essas respostas inconsistentes foram desconsideradas sistematicamente na análise. Os dados qualitativos oriundos das narrativas foram interpretados focando especificamente o uso das estratégias e seu impacto na formação desses alunos, tanto como aprendentes da língua, quanto como professores em formação. Trechos das narrativas foram citados em nossa análise com a sua respectiva identificação ${ }^{6}$.

${ }^{6}$ Cada narrativa foi identificada por duas letras (FR para os alunos de francês e IN para os de inglês) acompanhadas do número do ano em que ingressaram (10 para 2010, 11 para 2011) e de um número sequencial aleatório para cada uma. 


\section{Análise e Resultados}

Analisamos os dados distinguindo os diferentes tipos de estratégias entre si. Começando pelas estratégias cognitivas (ver tabela 1), a primeira observação que se pode fazer é que, embora essas estratégias estejam "no âmago do ato de aprender" (CYR, 1998, p. 47) e se encontrem normalmente entre as mais usadas, apenas duas das que foram citadas no questionário (relacionar conhecimentos novos com conhecimentos anteriores - n. 1; praticar a língua fora da sala de aula - n. 8) já eram utilizadas por mais da metade dos respondentes $(60 \%)$ quando entraram no curso.

As outras estratégias, tão elementares para o estudo de uma língua estrangeira quanto essas duas primeiras (reutilizar de diversas maneiras aquilo que se está aprendendo - n. 11; organizar, sistematizar os conteúdos estudados - n. 5; adotar atividades diferentes para desenvolver habilidades orais ou habilidades escritas - n. 15; diversificar as técnicas de aprendizagem - n. 10), eram praticadas por apenas $23,4 \%$ a $36,7 \%$ dos aprendentes e, ainda, em muitas respostas, só eram utilizadas “às vezes" (e até "quase nunca” em uma resposta).

Comparando os resultados da coluna 1 (que se refere a um estado anterior ao ingresso no curso, no que diz respeito ao uso de estratégias) com as colunas 2 e 3 (relativas à situação retratada no momento da pesquisa), observa-se que $40 \%$ a $56,7 \%$ dos aprendentes passaram a diversificar significativamente seu modo de interagir com a língua em estudo, em maior ("sempre") ou menor (“às vezes") grau, com o "quase nunca" aparecendo em apenas quatro ocorrências.

Nenhum dos respondentes julgou irrelevante alguma dessas estratégias, o que pode ser creditado ao trabalho feito na disciplina, pois cada uma delas era explicitada com base nas atividades de aprendizagem do manual de língua. Isso possivelmente ajudou os alunos a não considerá-las como mero aporte teórico. 


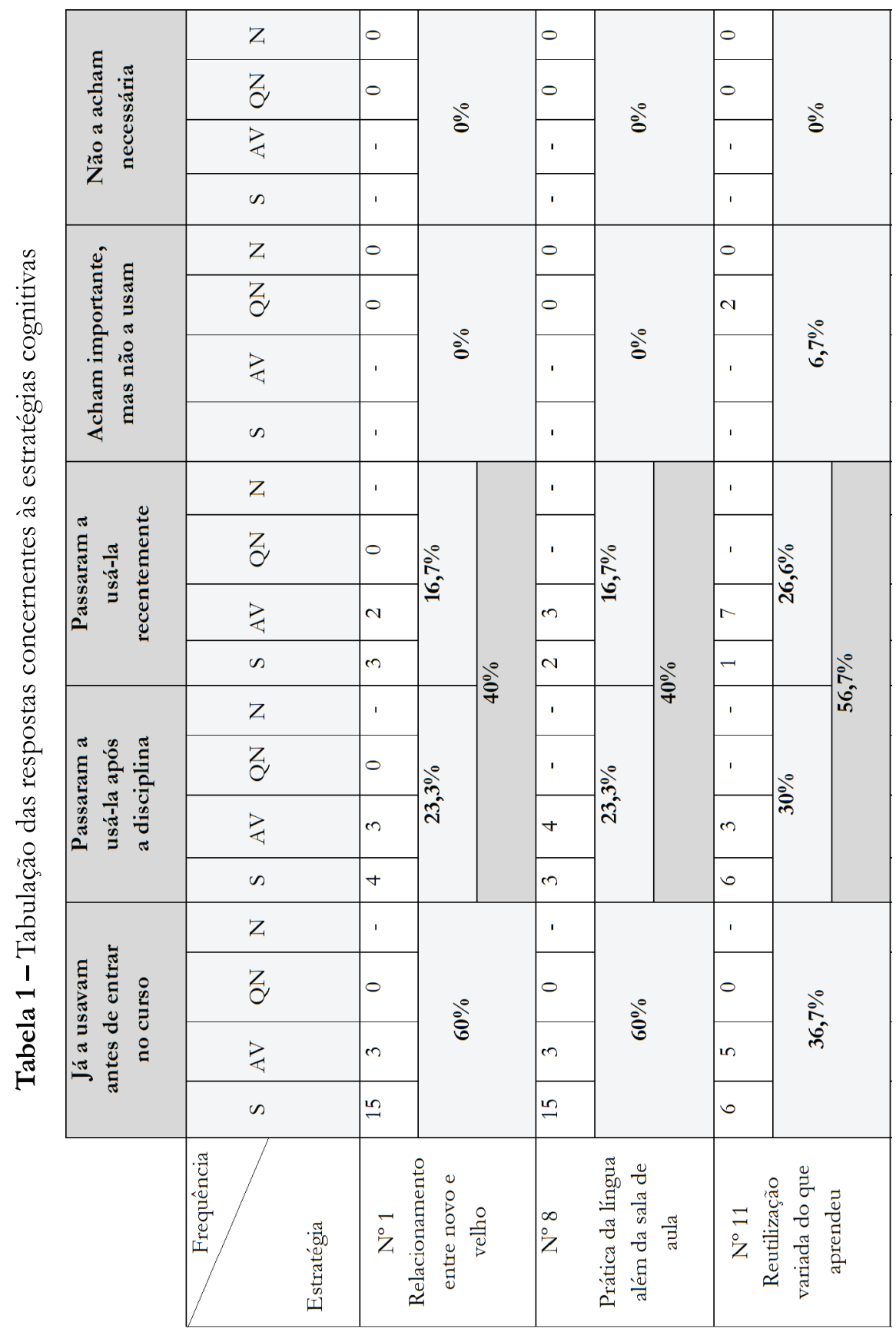




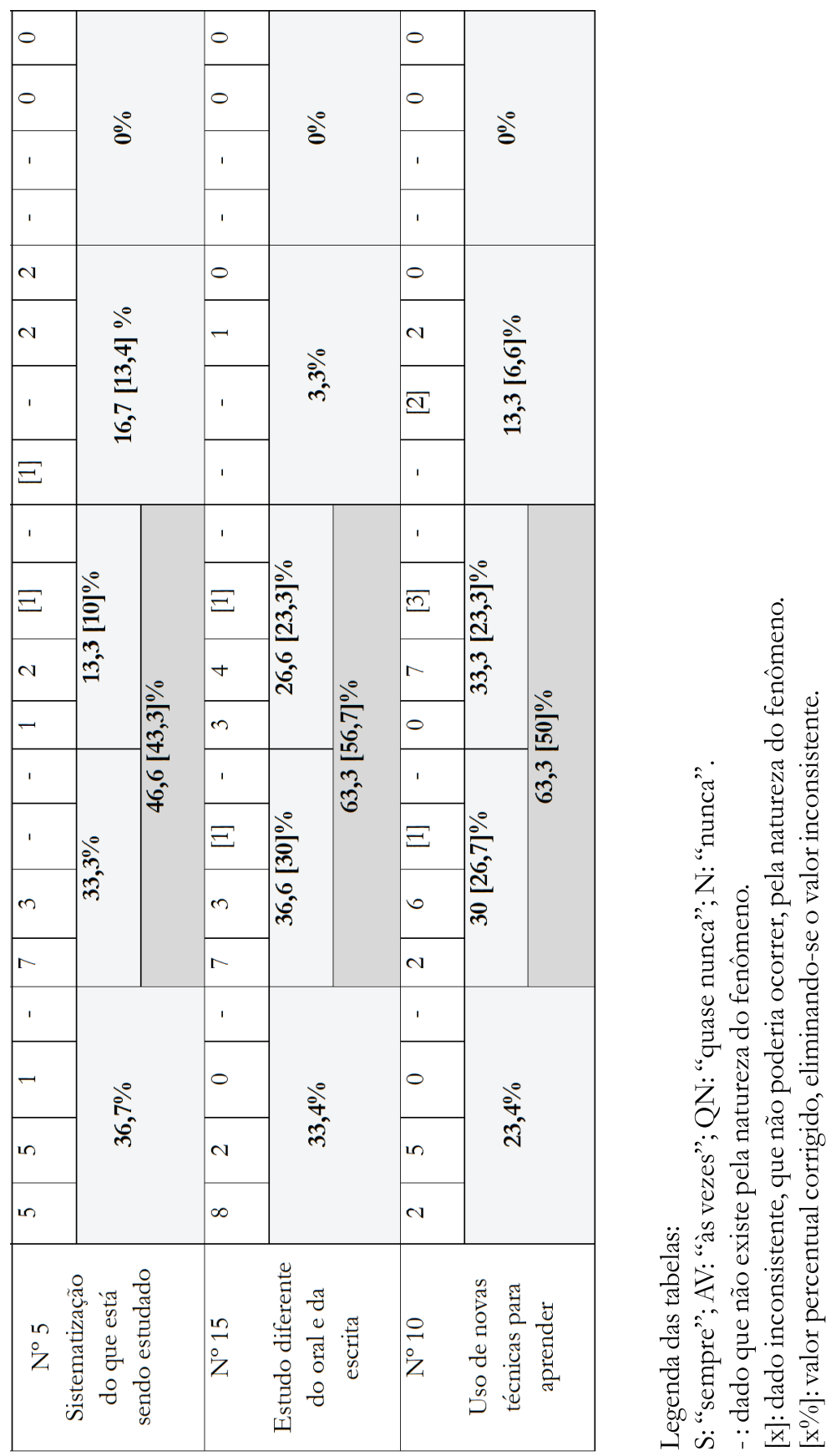


Todavia, a consciência da importância das estratégias não foi suficiente para que todos se apropriassem das estratégias em questão. De fato, na categoria "acham importante, mas não a usam", 3,3\% a 13,4\% dos respondentes reconheceram lançar mão "nunca" ou "quase nunca" de estratégias como sistematizar as muitas informações que surgem ao longo das atividades ou reutilizar de diversos modos aquilo que estão aprendendo. Possivelmente, esses se enquadram entre os aprendentes resistentes à mudança, na prática, por acreditarem - como resumiu uma aluna de francês ${ }^{7}$ - que "no fim, com nosso jeito de estudar tudo dará certo, como sempre deu: não entramos em uma universidade pública?", ainda que essas estratégias sejam claramente insuficientes. A esse grupo agregam-se aqueles que talvez vislumbrem a necessidade de mudança, mas não conseguem empreender o esforço necessário para disciplinar-se nos estudos.

No que diz respeito às estratégias metacognitivas, os dados computados na tabela 2, a seguir, permitem constatar que os respondentes faziam pouco uso desse tipo de estratégias antes do início do curso. Esses dados não surpreendem os professores da disciplina Ap/Ap confrontados, turma após turma, com a dificuldade da maioria dos aprendentes em adotar uma postura reflexiva. A autoanálise e autocorreção dos erros (n. 9) e a autoavaliação realista (n. 14) constituem exceções, tendo, ainda assim, um percentual de uso declarado relativamente baixo, de $40 \%$ e $26,7 \%$ respectivamente. Pode-se considerar que, direta ou indiretamente, essas estratégias são tradicionalmente mais solicitadas no sistema escolar. Embora a autoavaliação não constitua um objeto de aprendizagem explícito na escola, ela aparece como um subproduto de práticas escolares, particularmente focadas no exame.

Somente $13,3 \%$ a $20 \%$ dos respondentes declararam já se valer, antes de seu ingresso no curso, de estratégias como as de: identificação dos objetivos - n. 7; uso de estratégias novas - n. 4; planejamento do estudo - n. 16; organização do tempo de estudo - n. 2; e adaptação das atividades ao estilo pessoal - n. 12, o que é facilmente compreensível em um contexto educacional que, de um modo geral, pouco solicita a autonomia.

${ }^{7} \mathrm{O}$ comentário foi feito durante um aconselhamento sobre as dificuldades de aprendizagem dessa aluna, participante do Programa de Licenciatura Internacional na França (PLI-França), da CAPES, no seu quarto semestre de curso. A aluna ainda comentou que, enquanto não se defrontasse com o fracasso de seu modo habitual de estudar, não teria condições sequer de atentar para aquilo que tinha sido indicado pela professora. 


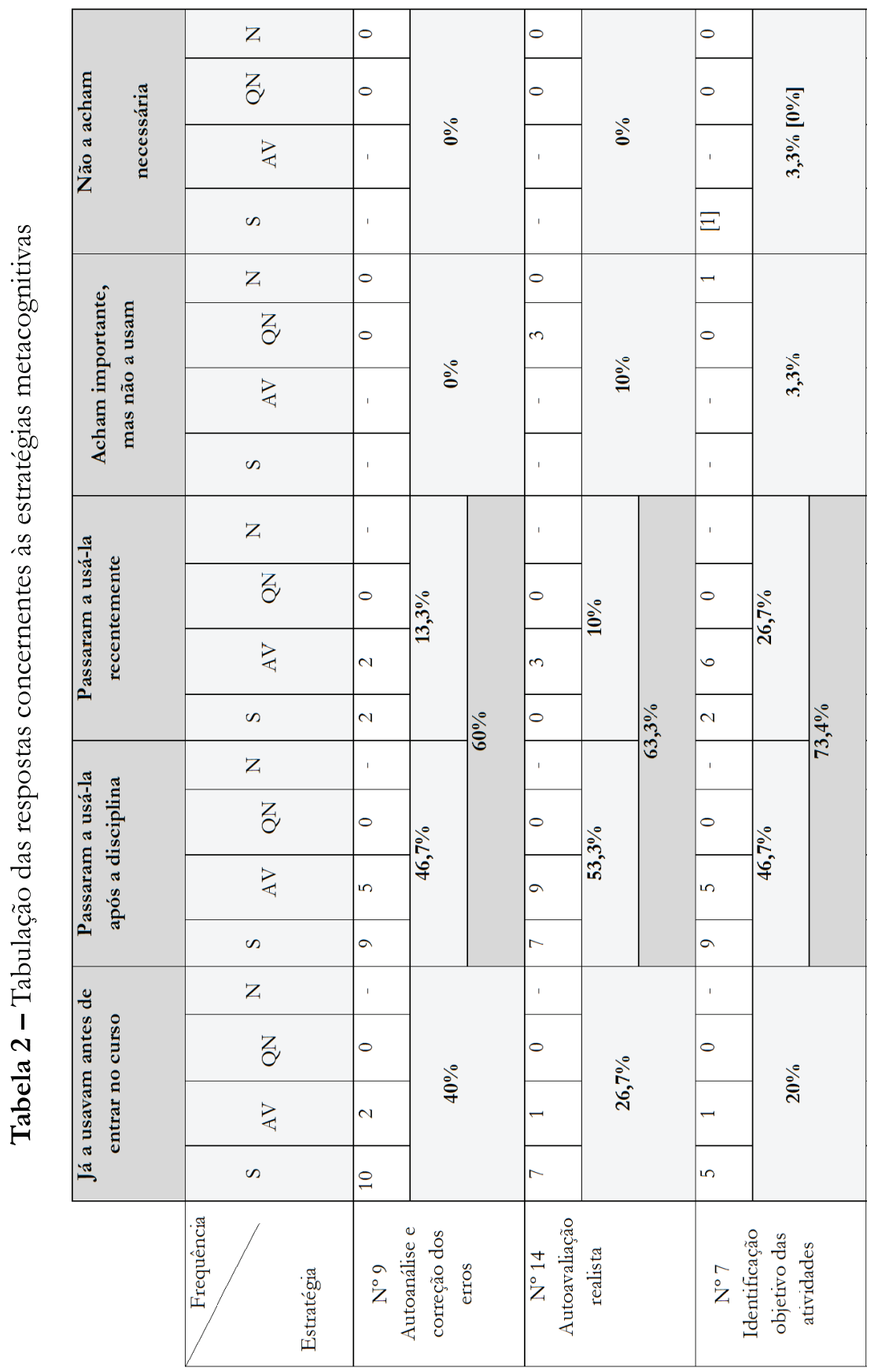




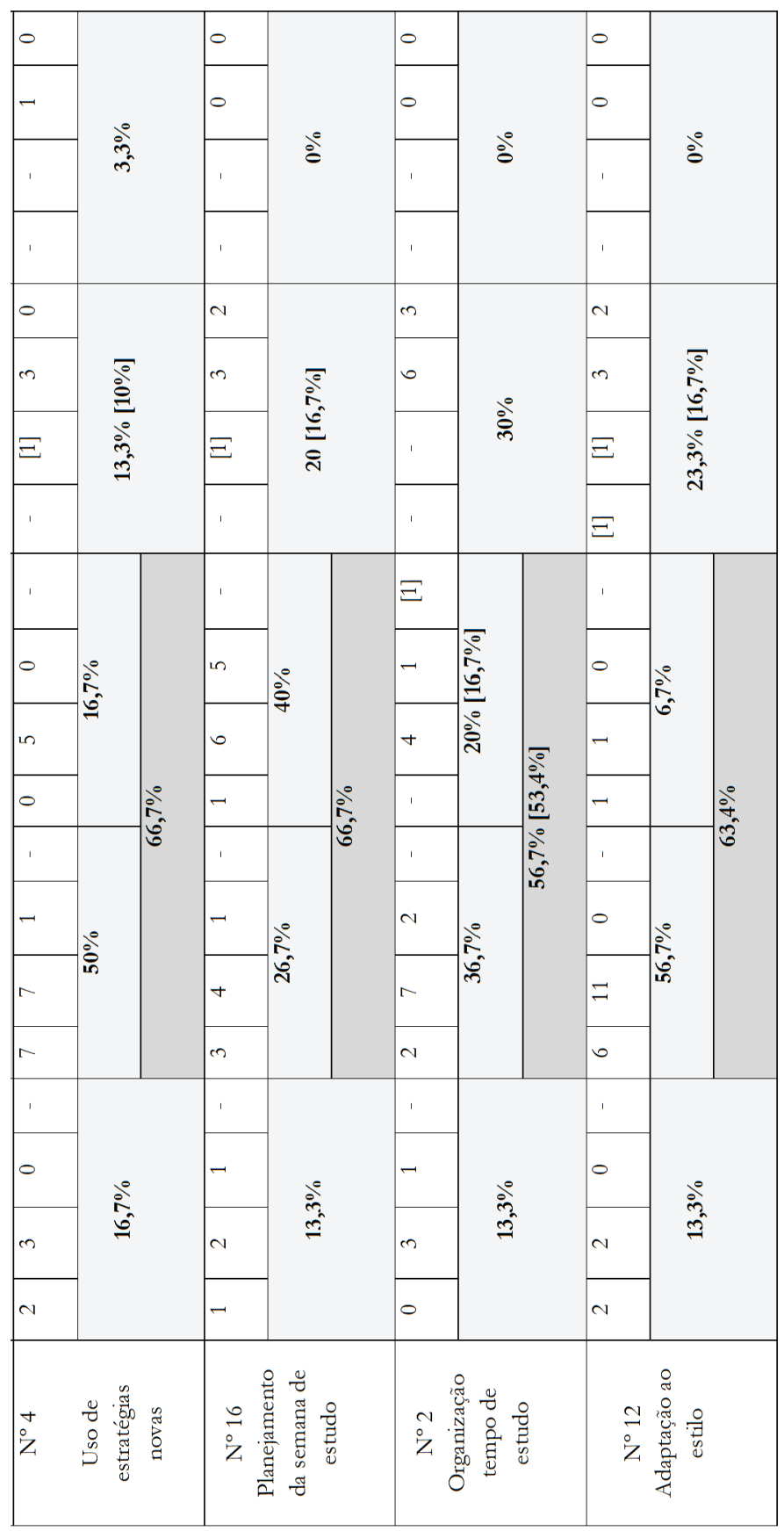

SIGNUm: Estud. Ling., Londrina, n. 17/1, p. 44-73, jun. 2014 
A disciplina Ap/Ap parece ter tido um bom impacto no desenvolvimento de todas essas estratégias, já que 53,4\% a 73,3\% dos respondentes passaram a utilizá-las logo depois de serem a elas apresentados ou o fizeram posteriormente. A estratégia que demorou mais para ser adotada foi o planejamento dos estudos ao longo da semana: 40\% declararam tê-la experimentado posteriormente. Pode-se pensar que o aumento progressivo do grau de complexidade na aprendizagem da língua estrangeira acabou convencendo os alunos da necessidade de experimentá-la. A objetivação da aprendizagem exigida pelas estratégias metacognitivas é um procedimento desconhecido da maioria e demanda um tempo para se transformar em nova habilidade. É o que ilustra o trecho (1), extraído de uma narrativa:

(1) Motivação, autonomia, estilos eram até então desconhecidos para mim. Como aprendente de línguas, melhorei minhas estratégias e pude mudar minhas ações, como organizar melhor meus horários, por ex. Claro que não foi instantâneo, somente enxerguei as minhas mudanças um bom tempo depois. (IN1010) ${ }^{8}$

Outro dado que se depreende da tabela 2 é que praticamente nenhum dos respondentes acha desnecessário o uso de qualquer das estratégias metacognitivas elencadas, o que leva a crer que a reflexão desenvolvida com base em atividades práticas no Ap/Ap consegue efetivamente conscientizá-los de sua importância. Nota-se que apenas um respondente afirma "quase nunca" lançar mão de estratégias novas, por achar isso desnecessário. Trata-se, todavia, de um aluno de francês bem sucedido que aplica ao estudo desse idioma um amplo leque de estratégias que já desenvolvera em uma aprendizagem autônoma anterior da língua inglesa.

Como ocorreu com as estratégias cognitivas, um pequeno percentual de alunos (3,3\% a 16,7\%) assume a importância de determinadas estratégias, porém não as pratica. Tratando-se de organização do tempo de estudo, esse percentual sobe para $30 \%$, ao que tudo indica por razões culturais. Mas a hipótese da resistência, também perceptível no decorrer das aulas, permanece. Mais do que uma simples resistência à mudança, parece haver, também, uma resistência à própria objetivação, na medida em que nem sempre a imagem

8 Em todos os excertos os grifos são nossos. 
que os aprendentes encontram no espelho que a disciplina lhes apresenta os agrada. Deixar de se questionar parece mais confortável, pois, mais ainda do que para as outras estratégias metacognitivas, é preciso amadurecer para lidar com autoavaliação e autorregulação, como indicam os excertos (2) e (3):

(2) Depois resolvi levá-la [a disciplina Ap/Ap] em consideração, refleti nas minhas estratégias e vi que eu não estava aprendendo de forma certa. [...] A mudança na minha aprendizagem começou quando percebi que podia usar as estratégias aprendidas, não ao pé da letra, mas basicamente comecei a enxergar minhas dificuldades e trabalhar nelas. (FR1002)

(3) Quando entrei no curso, ainda estava muito imatura, não tinha muita responsabilidade e nem sabia realmente se essa era a profissão que eu queria seguir. (FR1001)

Aliás, o "controle ou a gestão da dimensão afetiva pessoal que acompanha a aprendizagem" (CYR, 1998, p. 55) e se traduz em estratégias afetivas também parece ter sofrido um impacto positivo com as aulas de Ap/Ap, conforme mostra a tabela 3, a seguir.

Antes de ingressarem no curso, $40 \%$ dos respondentes já sabiam da importância de suas emoções na aprendizagem (n. 17) e 30\% dentre eles tinham consciência do papel desempenhado pela motivação (n. 18). Esses números, pouco elevados, sugerem que as emoções, principalmente negativas, ainda são vivenciadas pela maioria, quando ingressam no curso, como algo íntimo e incontornável. Como narra uma das estudantes no trecho (4), a experiência de se deparar com uma língua nova pode levar o aprendente a passar por grandes oscilações emocionais, o que influencia fortemente a motivação:

(4) Eu sempre amei inglês e me senti tão feliz quando entrei na universidade. Como eu nunca havia estudado inglês em uma sala de aula, me senti tão nervosa e assustada com os exercícios para conversar com os colegas, de como eu falaria de minha vida em outro idioma, medo do que o professor poderia achar do meu inglês. Era tudo tão novo e incomparável que até passou pela minha mente mudar de curso. (IN1008) 


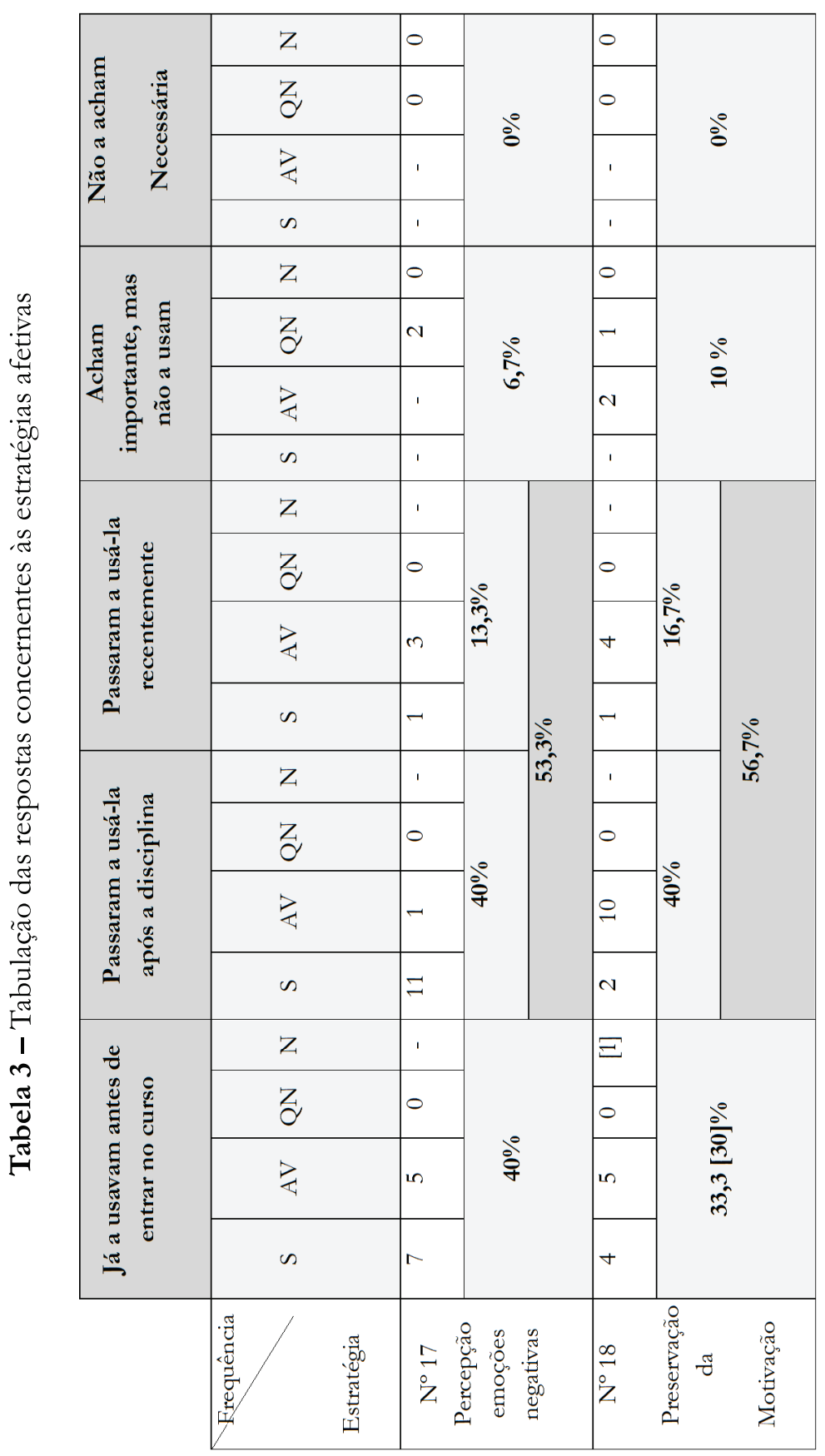


Ao tratar desses aspectos nas aulas de Ap/Ap, os professores percebem, pelos comentários e risadas, que explicitar os sentimentos que permeiam a experiência de aprender uma língua e designá-los como normais, partilhados pela maioria, causa alívio nos aprendentes e os ajuda a encarar mais serena e conscientemente essa dimensão da aprendizagem. Como alerta Rosário (1997, p. 413), reconhecer os aspectos afetivos é imprescindível para que não se criem bloqueios nos processos de regulação. De fato, "O desenvolvimento das capacidades de autorregulação não é um traço ou estágio de desenvolvimento cognitivo, mas sim um complexo processo interativo envolvendo componentes metacognitivos, mas também motivacionais". Uma das narrativas (excerto 5) evidencia esta ligação entre ausência de motivação e dificuldade no uso de estratégias bem sucedidas:

(5) Meu aprendizado do idioma francês foi iniciado sem muitas motivações, reprovei o segundo nível de língua [...] Atualmente, estou revendo assuntos que aprendi com falhas, e até os que não aprendi, de forma muito sistemática, o que possibilitou um aumento da minha autoestima e da minha motivação. (FR1101)

Já, no excerto (6) a aluna assume sua insegurança e instabilidade emocional, porém, à medida que essas características passam a ser reconhecidas como problemas, também são objeto de regulação por sua parte:

(6) Mas meus grandes problemas são confiar em mim mesma e ser uma pessoa muito fraca para os altos e baixos da vida (qualquer problema me deixa de baixo astral, sem motivação, não vale a pena colocar aqui). Sempre estou achando que não posso, não sou capaz, que eu não sou boa, vivo fugindo das oportunidades. Claro que não me prestava atenção [sic], mas [...] refleti a respeito e agora tento fažer mudanças. Nunca é tarde. (IN1010)

Pelos dados obtidos, 53,3\% e 56,7\% dos respondentes, respectivamente, passaram a se valer dessas estratégias. Todavia, ainda que nenhum aprendente julgue desnecessário lidar com suas emoções e sua motivação, uma pequena parcela ainda parece vítima de suas aflições de aprendentes. Embora sabendo que é importante controlar sua ansiedade ou seu medo do ridículo (para $6,7 \%$ ) e não deixar sua motivação desmoronar (para 10\%), ainda não conseguem fazê-lo, como mostra o excerto (7), em que a autora constata tristemente o fato, sem encontrar solução: 
(7) Devo admitir que ando bem desmotivada. Não apenas com o curso em si, mas com o meu aprendizado também. [...] Eu continuo estudando e me esforçando, mas sem nenhum prazer, só porque quero me formar. Sei que motivação é algo instável, que tem altos e baixos, mas creio que já estou há mais tempo do que gostaria com a motivação baixa. (IN1012)

Aqui, pode-se especular que a ausência de uma motivação inicial suficientemente forte ou efetivamente dirigida para o objetivo do curso (formar professores que também sejam falantes proficientes da LE) dificulta tanto a regulação da aprendizagem quanto da própria motivação.

Em relação às estratégias sociais, os dados apresentados na tabela 4, a seguir, não surpreendem: estratégias de cooperação com outros aprendentes (n. 3), já praticada por 53,3\% dos respondentes, são comuns nos hábitos de estudo dos estudantes brasileiros (embora sejam raramente praticadas em sala de aula) e são reforçadas pelo trabalho colaborativo comum no ensino de LE. O número de novos adeptos dessa estratégia (40\%) provavelmente não é maior por causa do estilo preferencial de certos alunos, que preferem estudar sozinhos. Possivelmente, são esses que reconhecem seu valor, mas quase nunca a praticam ou só a praticam quando não têm escolha, em sala de aula.

As aulas de Ap/Ap encorajam os alunos a se arriscarem em interações com nativos (n. 6), face a face ou por meios virtuais, apesar de muitos pensarem que só será possível quando tiverem bom domínio da língua. Observa-se, como resultado, um crescimento expressivo de $63,3 \%$ no uso dessa estratégia. Todavia, as oportunidades talvez não sejam tão numerosas para quem mora em uma região periférica do país e que nem sempre disponha de acesso fácil à internet, pois 44,7\% só conseguem se valer dessas interações “às vezes” ou "quase nunca".

A última estratégia considerada, a de participar de grupo de estudo (n. 13), é peculiar: por ela depender menos do aprendente e mais de outrem (que precisa organizar o grupo e lançar um convite aos possíveis participantes), poucos são os que já a praticavam $(10 \%)$ ou passaram a praticá-la $(13,3 \%)$ e numerosos $(60 \%)$ são os que talvez gostassem de ter essa oportunidade, mas não a têm. A narrativa do único respondente que considera a estratégia desnecessária mostra, como se vê no excerto (8), que, embora tenha tido frequentes oportunidades de conversar com nativos, prefere outras estratégias para incrementar suas habilidades orais: 


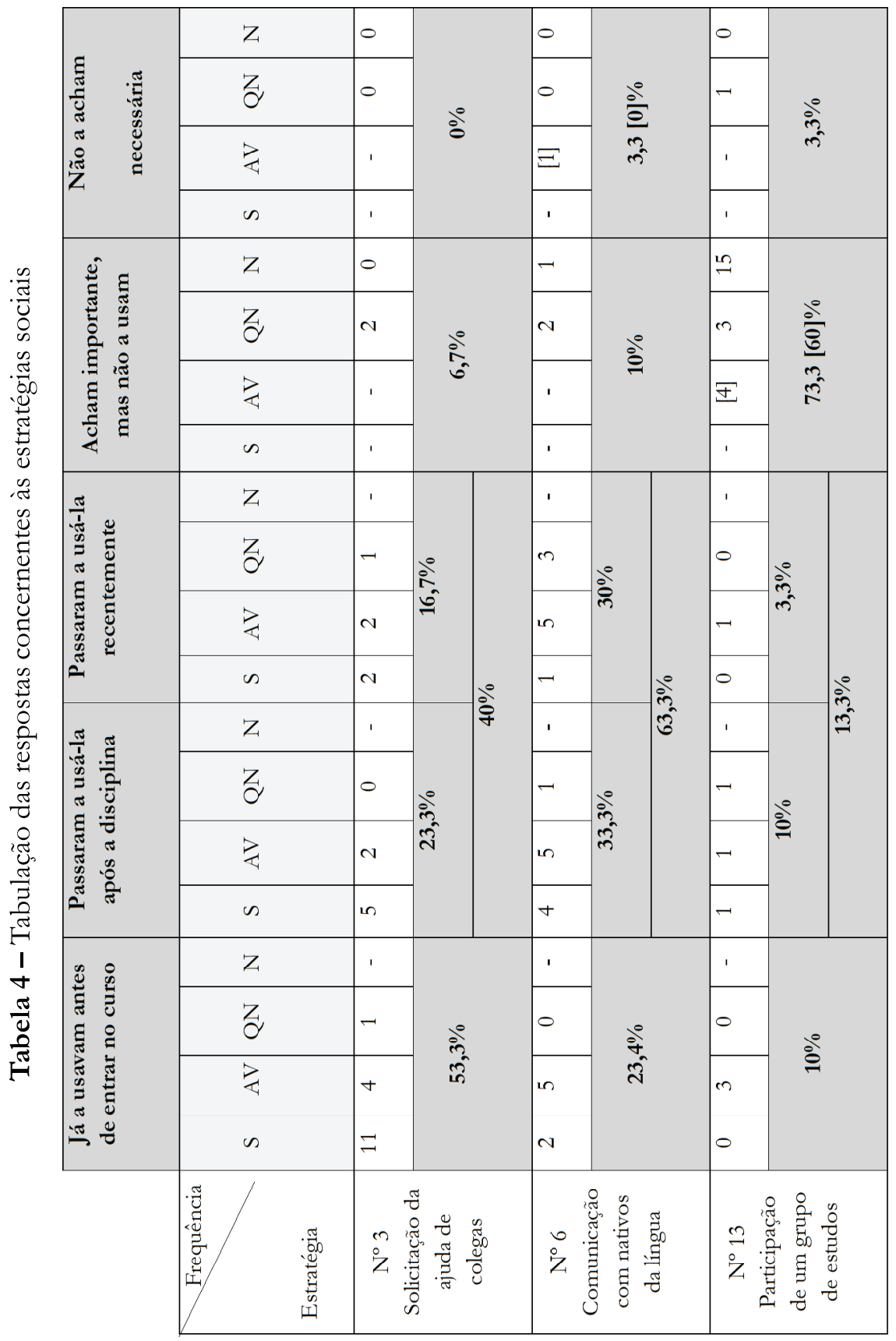


(8) I also have practiced oral conversations from 2010 up to now, and they have been more of the personal type than of the virtual one. It is due to the opportunities that I have had to speak to foreigners, in English, in my daily life and due to my lack of time to be online on FL learning and teaching sites. Actually, my virtual conversations have been practically typed. And I have always loved singing, and there is a long time that singing has helped me in my oral production in this language. I can practice it during nearly all of my spare time, and on my own too-different form a personal or virtual conversation, which requires two people at least. (IN1013)

Todos esses resultados foram sintetizados na tabela 5 que traz, na primeira coluna, o tipo das estratégias analisadas; na segunda, seu intitulado; na terceira, o percentual de estratégias que, conforme declarações dos sujeitos da pesquisa, já eram usadas por eles antes de ingressaram no curso; na quarta coluna, o percentual total de respondentes que passaram a utilizar cada estratégia logo depois da disciplina ou em algum momento posterior do curso; e, na última coluna, a soma dos resultados da terceira e quarta colunas. A tabela apresenta os totais da quarta coluna por ordem decrescente, para evidenciar onde houve maior desenvolvimento na adoção de novas estratégias.

Nota-se, em relação a esses dados, que 13 das 18 estratégias passaram a ser adotadas por mais de $50 \%$ dos respondentes. Das cinco outras, quatro passaram a ser usadas por $40 \%$ ou mais. Apenas o uso da última teve uma evolução pouco significativa, por razões já apontadas anteriormente. 


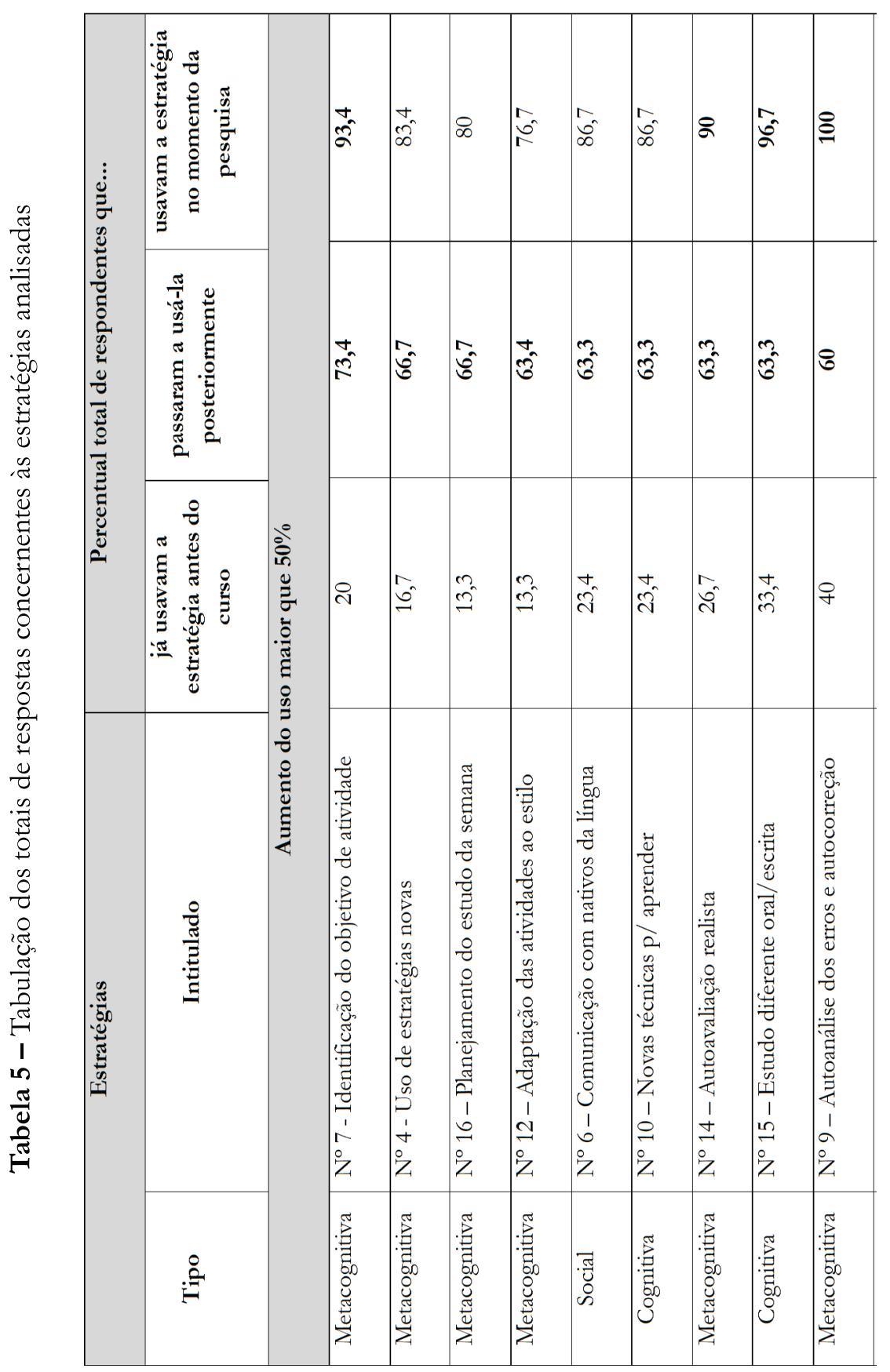




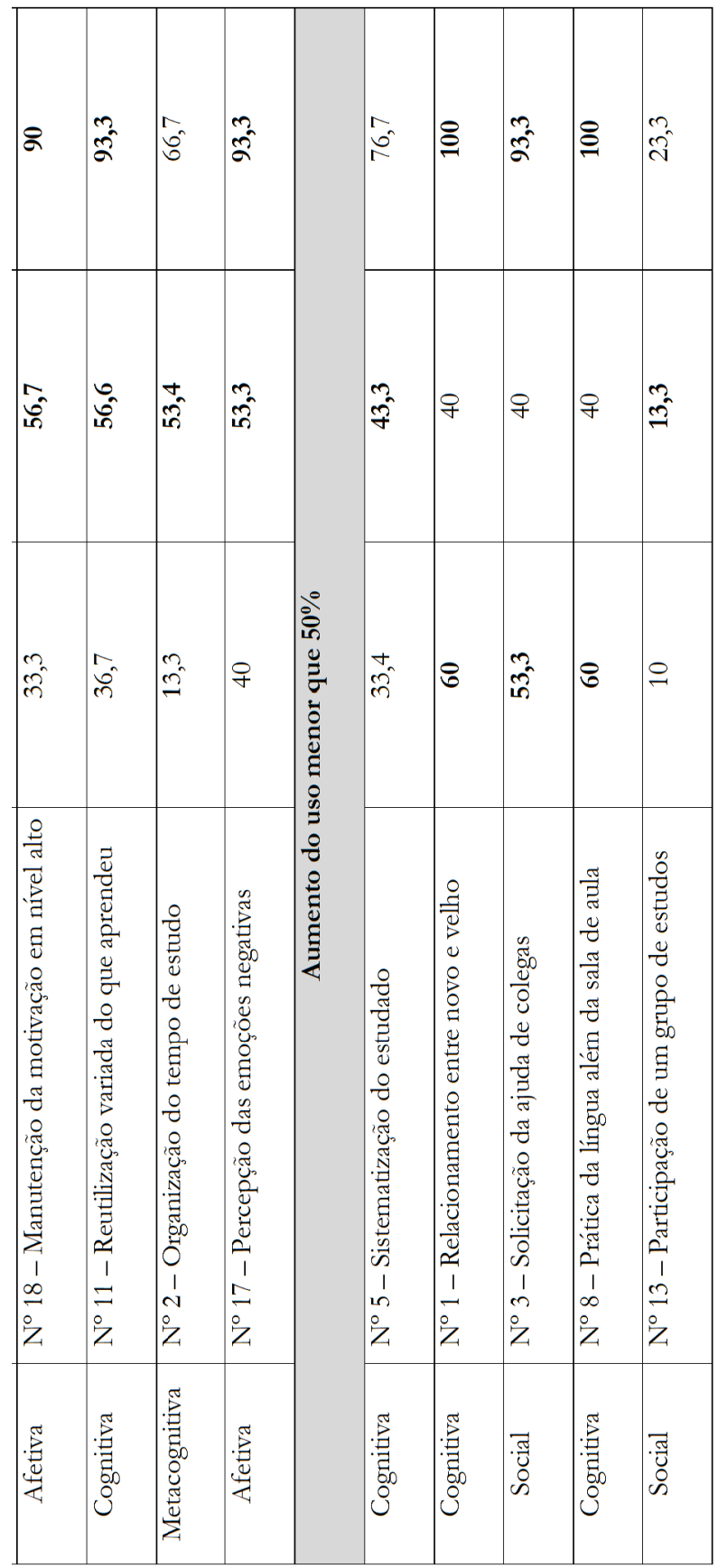


Em 15 das 18 estratégias pesquisadas o percentual de respondentes que passaram a praticá-las foi mais elevado do que o percentual de uso inicial (valores em negrito na terceira coluna). Nos três casos em que isso não ocorreu, o percentual total é igual a 100\% ou chega muito perto disso, o que significa que o aumento no uso das estratégias foi máximo.

Observa-se também, na última coluna, que dez entre as 18 estratégias mencionadas eram praticadas por $90 \%$ a $100 \%$ dos respondentes, no momento do estudo (valores negritados).

Essa evolução é encorajadora, na medida em que os respondentes encontravam-se ainda na primeira metade do seu curso ou mal estavam iniciando a segunda metade, estando em condições, portanto, de continuar a evoluir na mobilização de novas ações favoráveis à sua aprendizagem. De fato, há, nos depoimentos como nas observações empíricas das professoras, evidências de que nem sempre a evolução ocorre no ritmo desejado, isto é, imediatamente. Alguns alunos entendem muito rapidamente que podem ganhar com essa reflexão, como em (9):

(9) No segundo semestre de 2010 eu comecei meu curso de graduação em inglês. Eu já sabia algumas coisas, mas percebi que havia muito mais a aprender. A matéria Aprender a Aprender me ajudou muito a me conscientizar dos meus pontos fracos e como eu poderia trabalhar neles para melhorar. (IN1012)

Todavia, a reação mais frequente é de desconfiança, como em (10):

(10) Quando tive esta disciplina no começo da minha graduação, achei que ela não me servia muito porque tinha acabado de sair do ensino médio. Como é que uma aluna como eu iria ser madura o suficiente para aprender a analisar minhas estratégias de aprendizagem? Neste começo, achei a disciplina inútil para mim [...]. Somente depois de amadurecer pude constatar a [sua] importância na nossa aprendiragem. (FR1002)

Em muitos casos, a pertinência daquilo que é discutido na disciplina somente é percebida quando os aprendentes são confrontados com a inadequação de seus próprios métodos de estudo ou quando se deparam com o desafio de ministrar aulas, como exemplificado em (11) e (12): 
(11) Nos primeiros semestres no curso de Letras, comecei a refletir mais sobre minha própria aprendizagem, comecei a aceitar minhas próprias limitações e, o mais importante: entender o processo de aprendizado. Mais confiante fiquei ao ter ciência do meu estilo de aprendizagem e como deveria administrar aquilo ao men favor. Aos poucos conheci meus maiores erros e minha maior dificuldade [...] (IN1001)

(12) [...] desde que entrei no curso de francês e fiz a disciplina "Aprender a Aprender" muita coisa mudou. Aprendi a organizar horários, a descobrir minhas dificuldades e meu estilo de aprendizagem. Porém admito que tudo isso começou a fazer mais sentido quando comecei a passar meus conhecimentos de LE para meus alunos. (FR1001)

Além disso, os professores que experimentam esse tipo de objetivação de seu processo de aprendizagem em sua formação inicial certamente terão maiores condições de incentivar seus próprios alunos a seguir esse caminho. Encontramos pistas deste fenômeno nos excertos (12), acima, e nos trechos (13) a (15), a seguir. Na narrativa (13), a aluna/professora fala dos desafios que representou começar a ensinar sem saber muito mais do que a gramática do inglês, mas menciona a influência do que aprendia na universidade e, em particular, como partilhou sua vivência de uma das estratégias com seus alunos:

(13) Aliando minhas aulas na universidade à minha vida de professora, coloquei em prática tudo o que aprendia sem esforços. Ao ensinar, encontrei estímulos para aprender ainda mais. [...] Um fato motivador foi o meu primeiro contato com nativos! Foi uma experiência maravilhosa que no mesmo dia fiz questão de compartilhar com meus alunos. (IN1001)

(14) Durante essa primeira experiência de ensino, minha vida foi alavancada de aluna para aluna-professora em questão de meses, pois para ensinar eu precisava estudar e eu precisei me esforçar o dobro para acompanhar o ritmo da escola; e quando me dei conta eu já havia ultrapassado os níveis da minha expectativa e já colocava a teoria em prática em minhas aulas. (IN1008)

(15) A princípio eu queria sim ser professora, mas eu também tinha outros focos. Agora, é o que eu mais quero. Descobri como é 
fabuloso ajudar as pessoas através da educação. Meus pensamentos a respeito dessa profissão mudaram muito logo depois do primeiro semestre. (IN1010)

Em todo o caso, quando o aprendente toma consciência do que está fazendo e como, fica evidente a inter-relação no incremento das estratégias entre si e nos benefícios para a aprendizagem, como expõe o trecho (16):

(16) Since I studied 'Aprender a Aprender Linguas Estrangeiras', I became conscious about some factors that surely influence on the foreign language learning. [...] After I began setting my FL objectives very clearly, it got easier for me to evaluate the results and other aspects like time spent and benefit of the new knowledge. The FL learning tools have worked as allies for me [...]. The idea that 'progress' and 'mistake' both naturally participate in the FL learning has brought me the ability to analyze, by myself, where my development worked well and where I can improve it. (IN1013)

Analisando as diferenças entre tipos de estratégias, observa-se que as metacognitivas estão entre aquelas que mais se desenvolveram ao longo do curso, o que significa que o propósito declaradamente reflexivo da disciplina está sendo alcançado. As que passaram a ser praticadas por um número menor são a estratégia social "participar de grupos de estudo" (n. 13), pelos motivos já apontados, e a estratégia cognitiva "sistematizar o que foi estudado" (n. 5). Neste último caso, a cultura escolar, geralmente pouco estimuladora de autonomia, pode ser responsável por avanços menos significativos. Outra explicação plausível encontra-se em características do material pedagógico de apoio, que já propõe pequenos quadros resumindo o que está sendo objeto de aprendizagem. Os alunos parecem se contentar com esse material e resistem à ideia de preparar um material próprio, mais completo.

De um modo geral, a análise das narrativas reforça as observações feitas com base nos dados do questionário, pois, embora nem todos incluam $\mathrm{o} \mathrm{Ap} / \mathrm{Ap}$ entre as disciplinas que os ajudaram a se situar em relação à sua aprendizagem, a ideia de tomada de consciência sobre o modo como levam sua aprendizagem e a menção às possibilidades de regulação de seu percurso, decorrente dessa conscientização, estão claramente presentes. 


\section{Conclusão}

$\mathrm{O}$ estudo aqui relatado indicou que, apesar das restrições iniciais de muitos em relação ao Ap/Ap, os aprendentes passaram a ampliar bastante suas estratégias metacognitivas, monitorando melhor sua aprendizagem e avaliando-se de forma mais realista. Tal ampliação levou-os a diversificar seu manejo da LE, fortalecendo suas estratégias cognitivas. Também os ajudou a tomar consciência de que suas emoções e sua motivação eram dimensões importantes de sua experiência, que precisavam ser tratadas de modo a não se transformarem em obstáculo à aprendizagem. Finalmente entenderam que a cooperação com seus pares não era algo negativo, mas poderia ser exercido a favor da aprendizagem, contrariamente ao que ocorre no ensino básico, em que o trabalho individual é mais valorizado.

Certamente, parte desses avanços pode ser creditada à disciplina Ap/Ap, que busca ajudar os estudantes recém-ingressados no curso a objetivarem seu processo de aprendizagem, para que tomem consciência daquilo que depende de seu empenho pessoal, no estudo da língua, e modifiquem seus hábitos, quando necessário. É preciso lembrar, todavia, que a reflexão desenvolvida no Ap/Ap não se dá em circuito fechado e que parte desses avanços poderia ser analisada à luz de outras variáveis, como experiências vivenciadas em outras disciplinas, amadurecimento emocional e cognitivo, práticas vividas em outros contextos (de cursos livres paralelos, por exemplo), o que não era nosso propósito aqui.

Embora esses resultados sejam motivo de alento para se prosseguir na experiência da disciplina e aperfeiçoar o tipo de reflexão proposta, não podem ser ignoradas as limitações perceptíveis nas respostas mitigadas ("uso, mas nem sempre" ou "estou convencido que é importante, mas não consigo mudar minhas práticas”). Afinal, as tabelas de dados evidenciam os mesmos limites percebidos pelas professoras em aula, quando se deparam com certa resistência ao tentarem incentivar uma atividade reflexiva mais eficiente e mais imediata.

Tais limites mostram que os desafios possivelmente ultrapassem o âmbito da disciplina e precisem se estender tanto à formação do professor quanto à formação do falante da LE. O presente estudo já manifestou o efeito retroativo dessa reflexão, quando os aprendentes passavam a ministrar aulas de língua. Estudos em atual desenvolvimento tendem a mostrar que, nas aulas de LE, há uma forte regulação em torno do uso da língua, mas a 
regulação da aprendizagem resume-se, muitas vezes, a incentivos genéricos ao estudo, sem maiores explicitações das estratégias que poderiam surtir efeito. Isso leva a crer que o trabalho empreendido no Ap/Ap precisa ser reforçado e estendido no dia a dia da aprendizagem da LE. Essa constatação abre perspectivas a novos desdobramentos para se enfrentar o desafio de Aprender a Aprender.

\section{Apêndice}

Obs. Por uma questão de espaço, apenas a primeira afirmação do questionário reproduz as cinco opções oferecidas em cada uma delas.

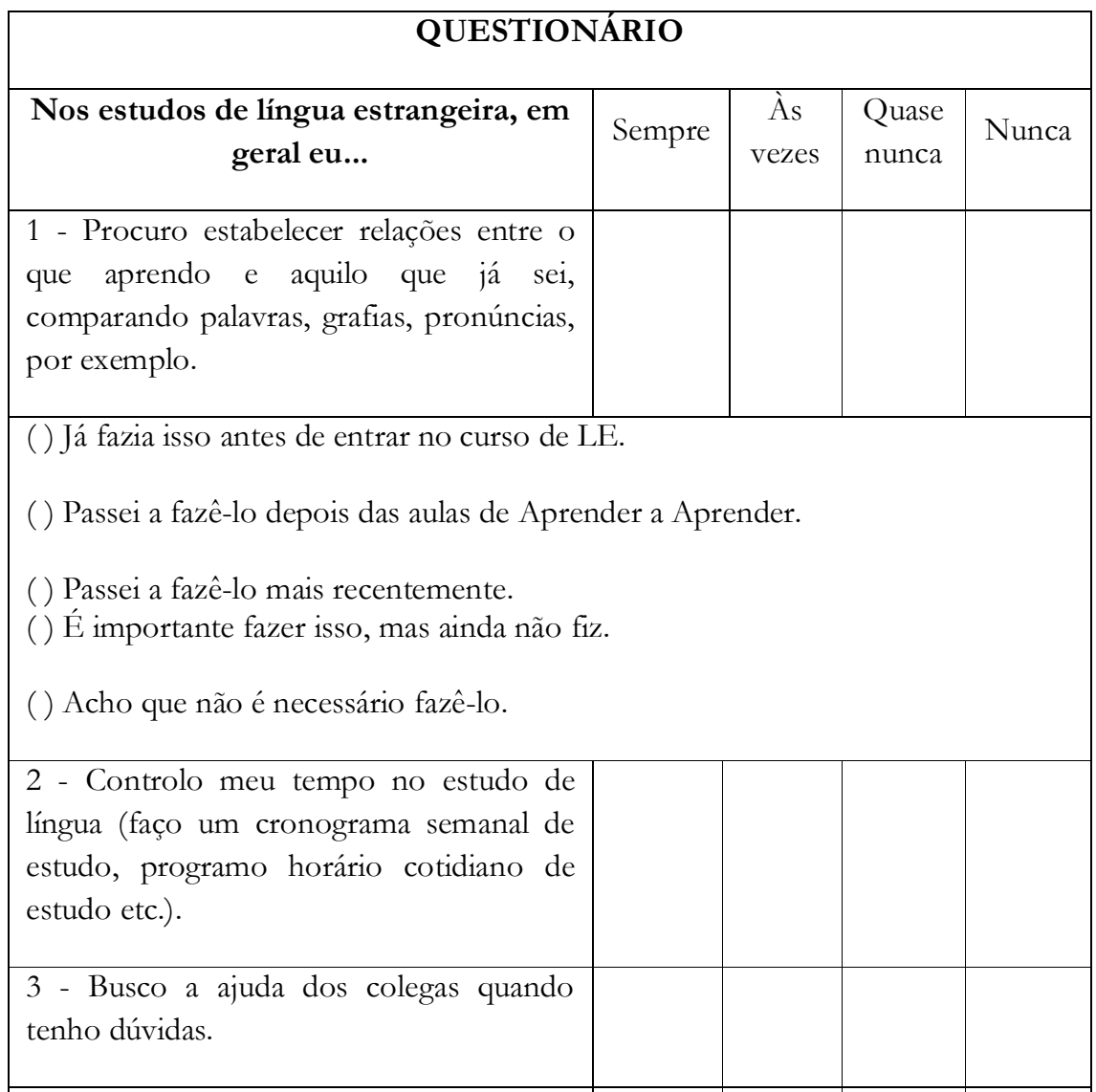




\begin{tabular}{|l|l|l|l|l|}
\hline 4 - Tento usar estratégias novas. & & & & \\
\hline $\begin{array}{l}5 \text { - Sistematizo e organizo o que está } \\
\text { sendo estudado em sala (faço listas, } \\
\text { quadros, pequenos resumos...). }\end{array}$ & & & & \\
\hline $\begin{array}{l}6 \text { - Comunico-me com nativos para } \\
\text { melhorar a aprendizagem da língua. }\end{array}$ & & & & \\
\hline $\begin{array}{l}7 \text { - Em cada atividade que faço, procuro } \\
\text { reconhecer qual objetivo está sendo } \\
\text { trabalhado. }\end{array}$ & & & & \\
\hline $\begin{array}{l}8 \text { - Busco praticar a língua além dos } \\
\text { limites da sala de aula. (músicas, sites na } \\
\text { internet, filmes, leituras...). }\end{array}$ & & & & \\
\hline $\begin{array}{l}9 \text { - Quando falo, procuro analisar meus } \\
\text { erros e me corrigir. }\end{array}$ & & & & \\
\hline $\begin{array}{l}10 \text { - Elaboro novas técnicas para } \\
\text { aprendizagem. }\end{array}$ & & & & \\
\hline $\begin{array}{l}11 \text { - Tento reutilizar o que aprendi de } \\
\text { várias maneiras. }\end{array}$ & & & & \\
\hline $\begin{array}{l}12 \text { - Sei adaptar as atividades de estudo a } \\
\text { meu estilo de aprendizagem. }\end{array}$ & & & \\
\hline
\end{tabular}

\section{Referências}

ALLAL, L. Régulations des apprentissages: orientations conceptuelles pour la recherche et la pratique en éducation. In: ALLAL, L.; LOPEZ, L. M. (Orgs.). Régulation des apprentissages en situation scolaire et en formation. Bruxelles: De Boeck \& Larcier, 2007. p. 7-23.

BENSON, P. Teaching and researching autonomy in Language Learning. Harlow, Essex: Pearson, 2001. 
BROWN, A. L.; BRANSFORD, J. D.; FERRARA, R. A.; CAMPIONE, J. C. Learning, remembering, and understanding. In: FLAVELL, J. H.; MARKMAN, M. (Eds.). Carmichael's manual of child psychology. v. 3. New York: Wiley, 1983. p. 77-166.

COHEN, A. D.; MACARO, E. (Eds.). Language learner strategies. Oxford: Oxford, 2007.

CYR, P. Les stratégies d'apprentissage. Paris: Clé International, 1998.

GU, P. Y. Foreword. In: COHEN, A. D.; MACARO, E. (Eds.). Language learner strategies. Oxford: Oxford, 2007. p. vii-viii.

HOLEC, H. Autonomy in Language Learning. Oxford: Pergamon, 1981.

O’MALLEY, J. M.; CHAMOT, A. U. Learning strategies in second language acquisition. Cambridge: Cambridge University Press, 1990.

OXFORD, R. Language learning strategies: what every teacher should know. Boston: Heinle \& Heinle Publishers, 1990.

ROSÁRIO, P. Aprendizagem auto-regulada: pensar o aprender, querer o aprender. A agenda dos anos 90? In: CONGRESSO LUSO-ESPANHOL DE PSICOLOGIA DA EDUCAÇÃO, 1., 1997, Braga. Anais... Braga: Apport, 1997. p. 405-414.

UNIVERSIDADE FEDERAL DO PARÁ. Projeto pedagógico do curso de Letras. 2009.

WENDEN, A. Conceptual background and utility. In: WENDEN, A.; RUBIN, J. Learner strategies in Language Learning. New York: Prentice Hall, 1987. p. 3-13.

Recebido em: 03/02/2014 Aceito em: 02/06/2014 